\title{
Design and Comparison of Closed loop Solar Water Pumping System with PID and FUZZY Controllers
}

\author{
A. Gopi Krishna ${ }^{1}$, M. Divya ${ }^{2}$ \\ M. Tech, Dept of EEE, Vignan Lara Institute of Technology and Science, Guntur, India ${ }^{1}$ \\ Assistant Professor, Dept of EEE, Vignan Lara institute of Technology and Science, Guntur, India ${ }^{2}$
}

\begin{abstract}
In developing countries, particularly many rural areas are in need of reliable and low cost electrical system which supplies water for rural areas. To solve this problem, an efficient water pumping system has to be designed to supply agricultural farms and rural settlement. For these applications, solar water pumping system is the most appropriate solution. This paper presents design and comparison of solar water pumping system with PID and FUZZY controllers for agricultural and domestic applications using MATLAB Simulink. In this project DC-DC boost converter is used to step up the voltage to a suitable value which is suitable to run the induction motor A design of directly coupled solar water pumping system powered from photovoltaic panels, DC to DC boost converter, full bridge sinusoidal pulse width modulation inverter, LC filter, induction motor and centrifugal pump is presented. The PID and FUZZY controllers used to control the voltage and compared the performance of the system with PID and FUZZY controllers.
\end{abstract}

Keywords: SPWM, PV arrays and solar panels, Boost converter, LC filter, PID, FUZZY controller and Induction motor.

\section{INTRODUCTION}

Solar energy has the greatest potential of all the sources of renewable energy. In order to make solar energy competitive with the other forms of renewable energies, a better exploitation of its advantages especially environmental side, this will be possible only with the development of the less expensive and high output efficiency systems.Now a days for stand-alone water pumping systems there have been papers published comparing other powered water pumping systems to solar-PV water pumping systems.

Pumping water is a universal need around the world and the use of photovoltaic power is increasing for this application. A solar powered pump is a pump running on the power of the sun. A solar powered pump can be very environmentally friendly and economical in its operation. The system operates on power generated using solar PV (photovoltaic) system. The photovoltaic array converts the solar energy into electricity, which is used for running the motor pump set.Photovoltaic is being employed around the whole world in most recent years. It is widely used in many applications in islands and remote areas. Using photovoltaic as the power source for water pumping is considered as one of the most promising areas of PV application. The PV water pumping system generally consists of PV array, inverter, and controller, motor, pump and water storage tank. The applications of solar energy which are enjoying most success today are solar water heating, solar cookers, food refrigeration, solar furnaces and solar photovoltaic (PV) cells. The water can be pumped during day times and stored in tanks. And also it makes water available in nights and also in cloudy climate conditions.

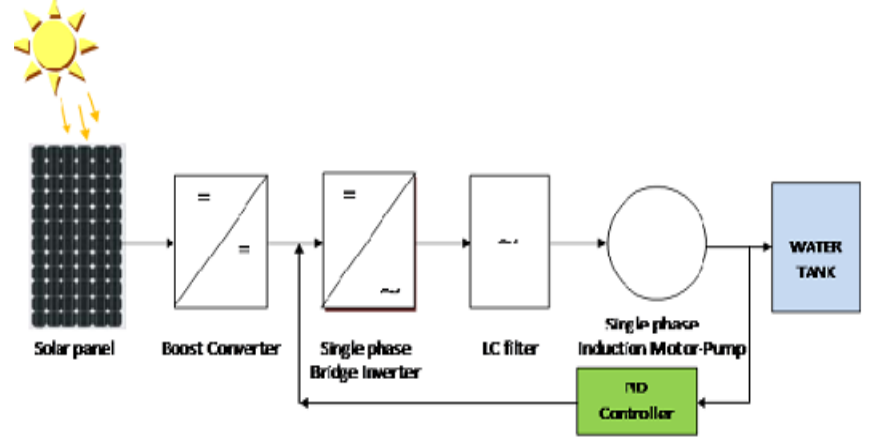

Fig. 1.1 Block Diagram of Solar Water Pumping System 
This paper also presents the design and analysis of a LC output filter for IGBT-based motor drive inverters. The LC filter is used to limit the rate of rise of the inverter output voltage and reduce common mode noise to the motor. By using a LC-filter pure sine wave is obtained which can be directly used to drive a single-phase induction motor. The pumped water can be used for many applications like domestic water, water for irrigation and to supply the water to villages.

The main benefits of the water pumps powered by photovoltaic systems are low maintenance, ease of installation, reliability and the matching between the powers generated and the water usage needs. In this paper an attempt is made to use a single phase induction motor which is more robust, less expensive and requires less maintenance compared to DC commutated motor.

The induction motor is driven by a full bridge single phase sinusoidal pulse with modulation (SPWM) inverter whose firing strategy has been designed so as to eliminate lower order harmonics [1]. This helps in reducing torque pulsations and unnecessary heating caused by harmonic currents and also improves system efficiency.

The voltage is controlled by using the PID feedback controller. The pump converts the mechanical energy in to hydraulic energy hence the AC pumping system is powered by PV cell.

\section{SOLAR PANNELS}

The use of new efficient photovoltaic solar cells (PVSCs) has emerged as an alternative measure of renewable green power, energy conservation and demand side management. Due to the initial cost of those PV cells, they have not yet been fully an attractive alternative for electricity users. The physics behind photovoltaic is helpful in understanding the equivalent circuits used to model it. Photovoltaic cells are semiconductor devices; the vast majority of commercial PV cells are fabricated from silicon. A PV cell is essentially a large diode that produces a voltage when exposed to incident light. It may be considered to be a light-emitting diode run backward; the analogy is similar to a heat engine and a refrigerator. The PV generator is a non-linear device and is usually described by its equivalent circuit and the I-V characteristics

The current and the voltage parameters of the PV generator are:

$$
\mathrm{I}_{\mathrm{PV}}=\mathrm{I} \text { andV } \mathrm{PV}_{\mathrm{PV}}=\mathrm{N}_{\mathrm{S}} \mathrm{V}
$$

Where is the number of series cells in the panel. The PV generator consists of solar cells connected in series and parallel fashion to provide the desired voltage and current required by the load

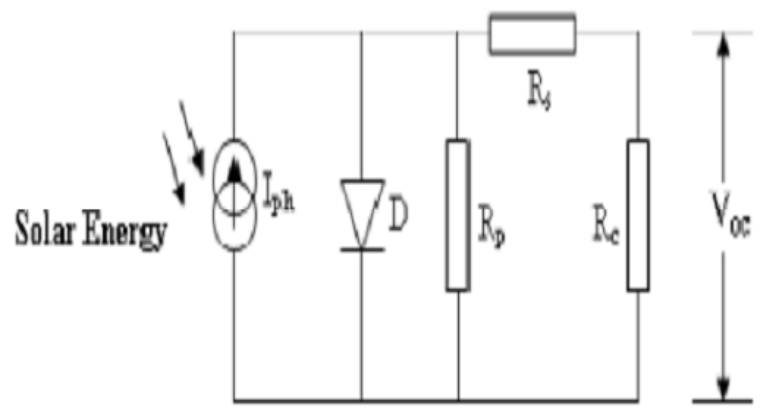

Fig. 2.1 Solar Cell

In space, the most powerful source of energy is the sun. To calculate the power necessary we must make some assumptions. The first is that we will have five solar panels on the satellite (one side will house the flashbulb and antenna).

Next we will assume:

- Intensity of the Sun $=1367 \mathrm{~W} / \mathrm{m}^{2}$

- Solar cell efficiency $=28 \%$

- Surface area of One Side $=83 \mathrm{~cm}^{2}$

- Solar Panels = 5

- Packing Factor = 60\%

- Factor to account for Free Rotation = 1/4

- Degradation of Gas Cells per year $=2.75 \%$ 
The single most important decision in this process was the choosing of the solar cells. As was mentioned earlier in the introduction, two major manufactured materials exist for solar cells. The first is silicon. Silicon was the material of the first solar cells and nowadays is mostly used in terrestrial settings due to its low production cost and low efficiency.

\section{BOOST CONVERTER}

The step up DC-DC converter is known as boost converter. In this the average output voltage is always greater than the DC input voltage. The output voltage is controlled by controlling the switch duty cycle. The main applications of the boost converters are in regulated DC power supply and the regenerative braking of DC motors. When the switch is on, the diode is reverse biased, and hence isolates the output stage. During the switch on mode the inductor gets the energy from the supply and stores it. During switch off state, the diode becomes forward biased and the output stage receives the energy from the inductor as well as the input. Thus the net energy transferred to the output from input is always greater in a given switching cycle. The ratio of output voltage to input voltage is given by

$$
\frac{\mathrm{V}_{\mathrm{o}}}{\mathrm{V}_{\text {in }}}=\frac{1}{1-\mathrm{D}}=\frac{\mathrm{I}_{\text {in }}}{\mathrm{I}_{0}}
$$

Where, Vo and Vin are the output and input voltages, respectively. The term Io and Iin are the output and input currents, respectively. The term $\mathrm{D}$ is the duty ratio and defined as the ratio of the on time of the switch to the total switching period. The figure 3.1 shows the basic configuration of Boost Converter.

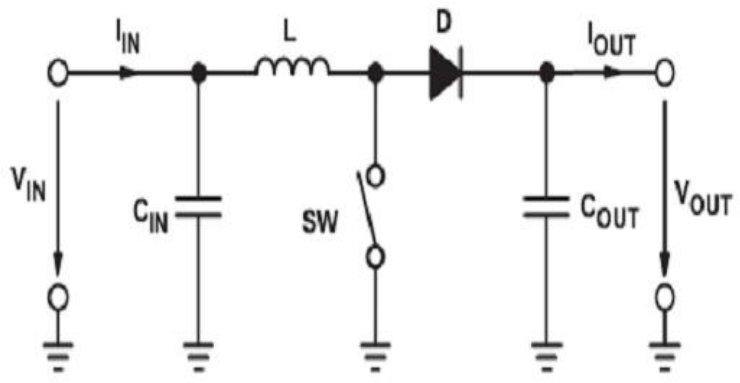

Fig. 3.1 Basic Configuration of Boost Converter

The switch is integrated in the used IC. Often lower power converters have the diode replaced by a second switch integrated into the converter. The first stepis to calculate the switch current to determine the duty cycle $\mathrm{D}$, for the minimum input voltage. The minimum input voltage is used because it leads to the maximum switch current.

Design of the inductor L is very important and critical step in the Boost Converter design. The switch SW is replaced with a MOSFET. Diode D is a schottky diode which offers a very small recovery period with a minimum voltage drop across it during ON period. The metal semiconductor junction is responsible for the low voltage drop.

$$
\mathrm{D}=1-\frac{\mathrm{V}_{\mathrm{IN}(\min ) * \eta}}{\mathrm{V}_{\text {out }}}
$$

$\mathrm{V}$ IN $(\min )=$ minimum input voltage.

VOUT $=$ desired output voltage.

$\eta=$ efficiency of the converter.

The efficiency is added to the Duty cycle calculation because the converter has to deliver the dissipated energy also. The next step is to calculate the maximum switch current to determine the inductor ripple current

$$
\Delta \mathrm{I}_{\mathrm{l}}=\frac{\mathrm{V}_{\mathrm{IN}}(\min ) * \mathrm{D}}{\mathrm{f}_{\mathrm{s}} * \mathrm{~L}}
$$

V IN $(\min )=$ minimum input voltage.

$\mathrm{D}=$ duty cycle.

$\mathrm{fS}=$ minimum switching frequency of the converter

$\mathrm{L}=$ Selected Inductor Value.

The inductor value can be obtained by using formula given below

$$
\mathrm{L}=\frac{\mathrm{V}_{\text {IN }} *\left(\mathrm{~V}_{\text {OUT }}-\mathrm{V}_{\text {IN }}\right)}{\Delta \mathrm{I}_{1} * \mathrm{f}_{\mathrm{S}} * \mathrm{~V}_{\text {OUT }}}
$$

The lower the inductor value, the smaller is the solution size. 
UGC Approved Journal

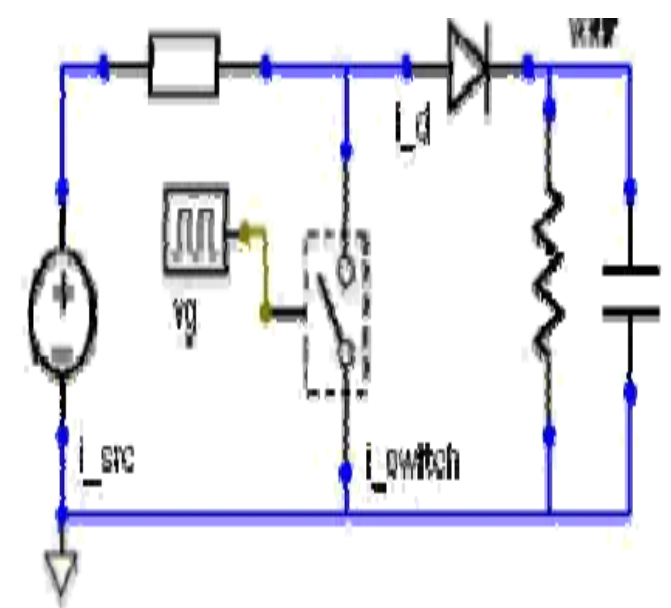

Fig.3.2 : The Schematic Circuit for the Boost Converter.

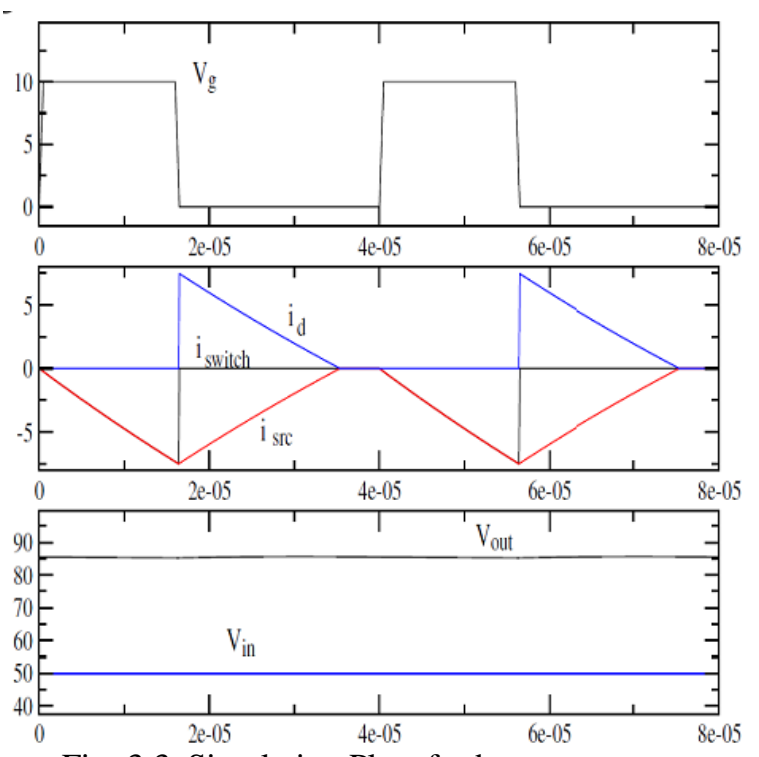

Fig: 3.3. Simulation Plots for boost converter

\section{SINUSOIDAL PULSE WID DTH MODULATION}

In SPWM technique it maintains the pulses in different widths instead of maintaining in equal widths as in multi pulse width modulation where the distortion factor (DF) and lowest order harmonics (LOH) are significantly reduced. The sinusoidal pulse width modulation (SPWM) technique is used to produce the sinusoidal waveform by filtering an output pulse waveform with varying width. A better filtered sinusoidal output waveform can be obtained by using a high switching frequency and by varying the amplitude and frequency of a reference or modulating voltage. The figure 4.1 depicts the six step inverter composed with six switches S1 to S6 with each phase connected to the middle of each inverterleg.

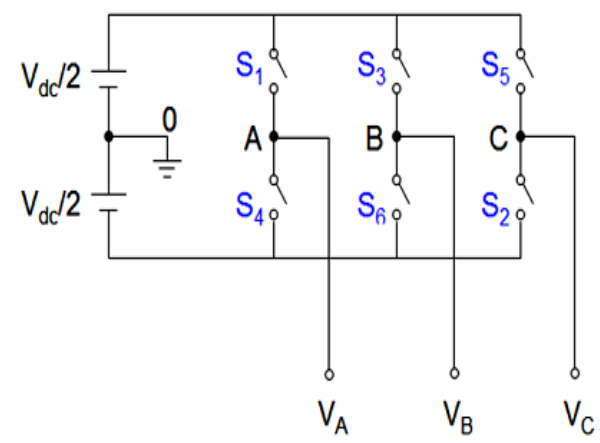

Fig. 4.1: Three Phase 


\section{UGC Approved Journal}

Figure 4.2 represents the control singal generated for SPWM In this we use triangular wave as carrier singal and sine wave as a reference signal and compare the two waveform with the help of comparator [3].

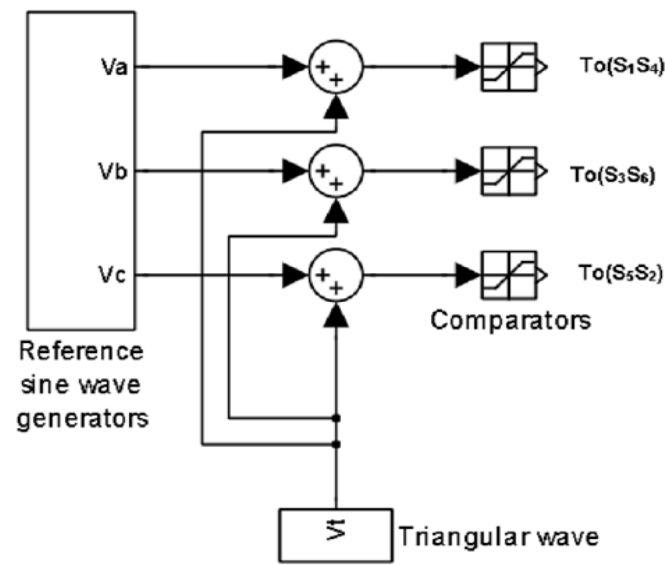

Fig. 4.2: Control signal generator for SPWM

The sample output voltage waveform using sinusoidal pulse width modulation technique along with the output voltage per phase to phase and phase to neutral are shown in figure 4.3.

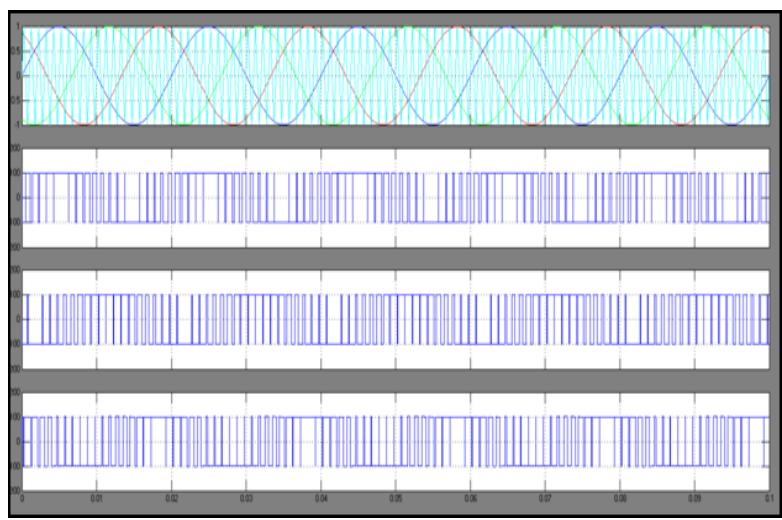

Fig. 4.3: output voltage using SPWM

The modulation ratio can be defined as the ratio of the magnitude of the output voltage generated for SPWM to the fundamental peak value of the maximum square wave.

$$
\mathrm{m}_{\mathrm{a}}=\frac{\mathrm{V}_{\mathrm{PWM}}}{\mathrm{V}_{\mathrm{max}}-\text { sisstep }}=\frac{\mathrm{V}_{\mathrm{dc}} / 2}{2 \mathrm{~V}_{\mathrm{dc}} / \pi}=\frac{\pi}{4}=78.55 \%
$$

Where the maximum output voltage is generated by a SPWM and is the fundamental peak value of a square wave. The frequency modulation ratio is defined as the ratio of frequency of the carrier wave to the frequency of the modulating (reference) signal.

$$
\mathrm{m}_{\mathrm{f}}=\frac{\mathrm{f}_{\mathrm{c}}}{\mathrm{f}_{\mathrm{o}}}
$$

Where the frequency of the carrier is signal and is the frequency of reference signal, the value of is to be chosen in order to suppress the harmonics.

\section{DESIGN OF LC-FILTER}

Filters play a key role in the inverter driven loads. It is mainly used for two reasons. They are necessary to convert the inverter output (i.e., square wave) into pure sinusoidal wave and to eliminate the higher order harmonics.In this paper LC filter is used. LC filter is a second order filter and it has filtering ability than L-filter. This simple configuration is easy to design and it works mostly without problems. Conversion of square wave in to sine wave. Here Filters are used to eliminate higher order harmonic where as lower order harmonics are eliminated by using SPWM technique. The basic design of the LC filter is shown in the figure 5.1 
UGC Approved Journal

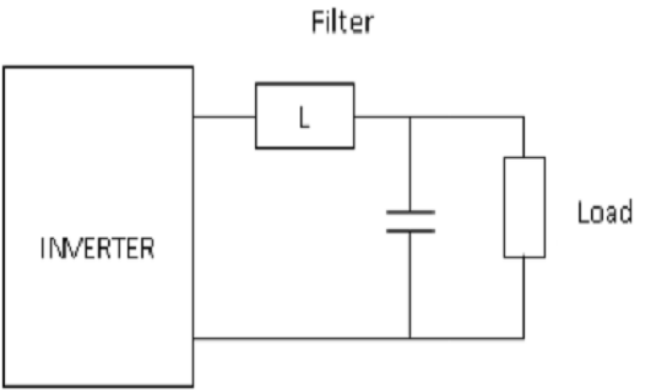

Fig: 5.1. Basic block diagram of LC filter

The basic block diagram of LC-filter is shown in 5.1. in designing the LC -filter the first step is finding the best filter and the second step is calculating the designed impedance from the lowest voltage (Vmin) divided by the highest current (Imax) is Rd and the third step is equating the inductor $(\mathrm{L})$ and the capacitor $(\mathrm{C})$ values.

$$
\mathrm{Rd}=\mathrm{Vmax} / \mathrm{Imax}
$$

The inductance $(\mathrm{L})$ and the capacitance $(\mathrm{C})$ values can be obtained by the following equations.

$$
\begin{gathered}
\mathrm{L}=\frac{\mathrm{R}_{\mathrm{d}}}{2 \pi \mathrm{f}}(9) \\
\mathrm{C}=\frac{1}{2 \pi \mathrm{fR}_{\mathrm{d}}}(10)
\end{gathered}
$$

Therefore by using the LC filter the harmonics can be reduced and sine wave is given to the induction motor.

\section{SIMULINK DESIGNSAND RESULTS OF SOLAR WATER PUMPING SYSTEM}

The single most important decision in this process was the choosing of the solar cells. As was mentioned earlier in the introduction, two major manufactured materials exist for solar cells. The figure 6.1 represents the design of solar panel using Simulink.

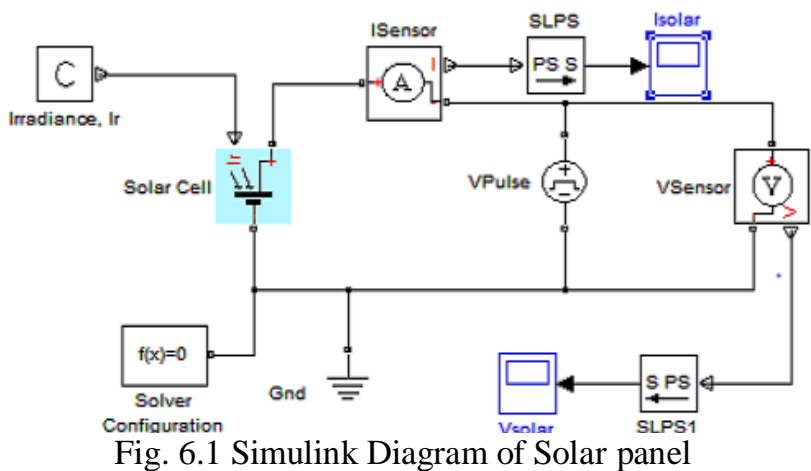

The most efficient method of doing this is by Width Modulation (PWM) control used within the inverter in this scheme the inverter is fed by a fixed input voltage and a controlled ac voltage. The figure 6.2 shows the inverter using the IGBT.
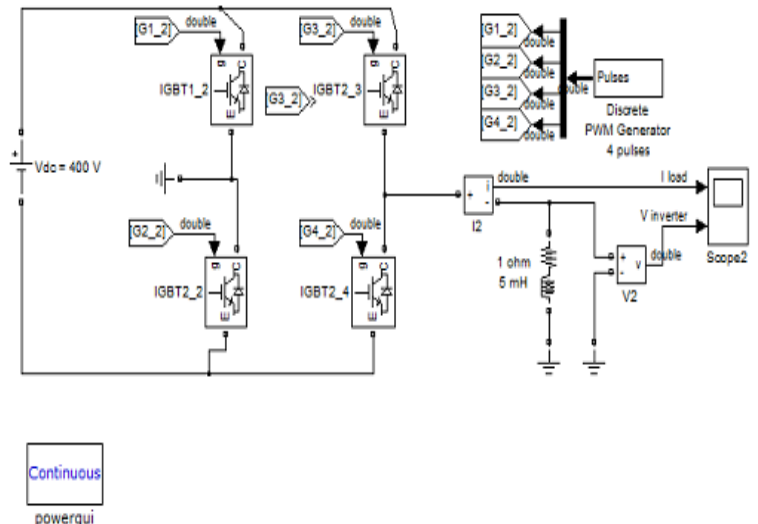

Fig.6.2 Inverter using IGBT 


\section{UGC Approved Journal}

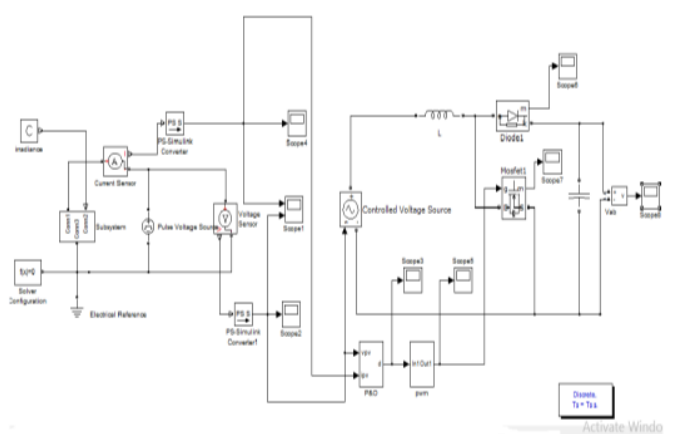

Fig.6.3solar input fed boost converter with mppt

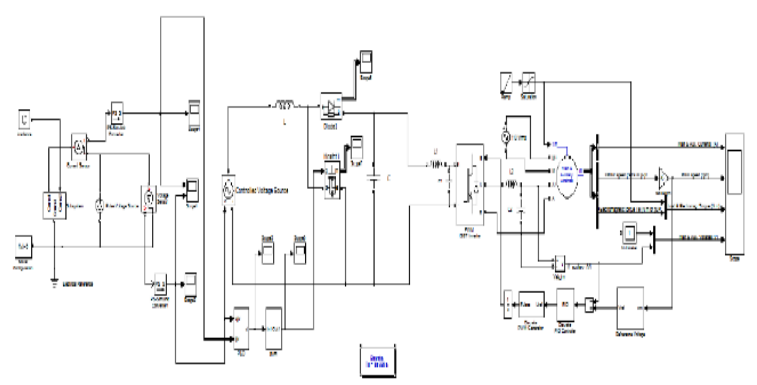

Fig. 6.4 simulation diagram of Solar Water Pumping System using PID controller.

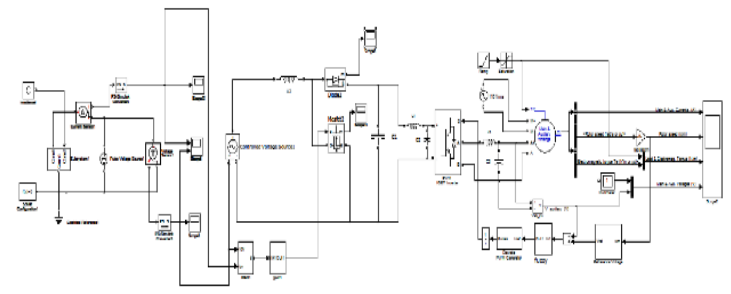

Fig. 6.5simulation diagram of Solar Water Pumping System using PID controller

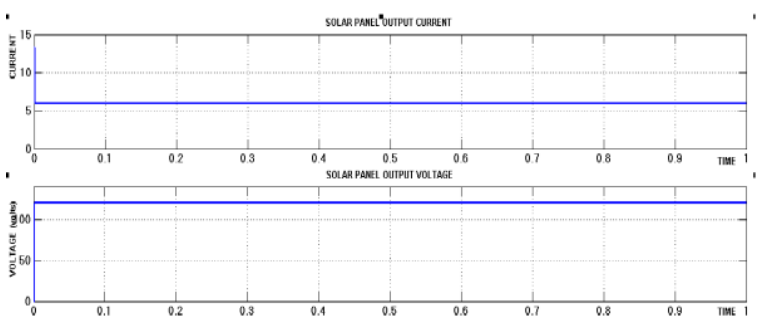

Fig. 6.6 Output current and output Voltage of solar panel.

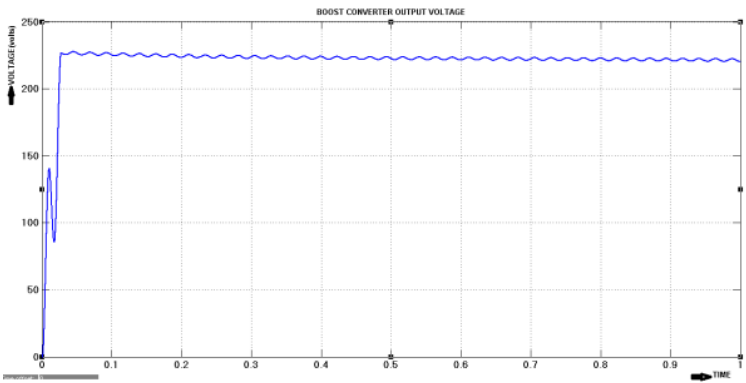

Fig. 6.7 Output voltage of boost converter 
UGC Approved Journal

IARJSET

ISO 3297:2007 Certified

Vol. 4, Issue 6, June 2017

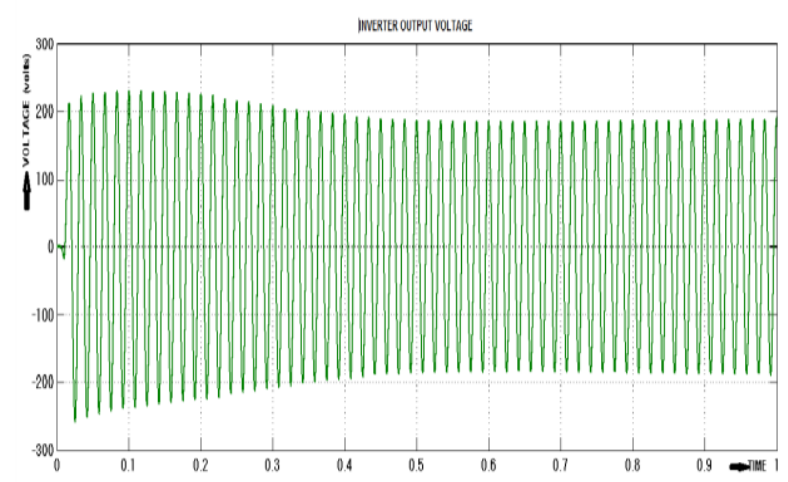

Fig. 6.8 Output voltage of inverter

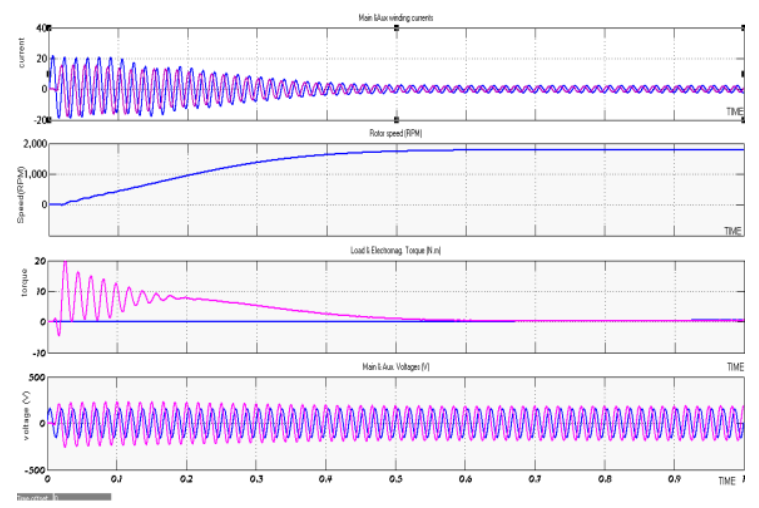

Fig. 6.9 Auxiliary and main currents, voltages, torque and speed of the induction motor with PID controller.

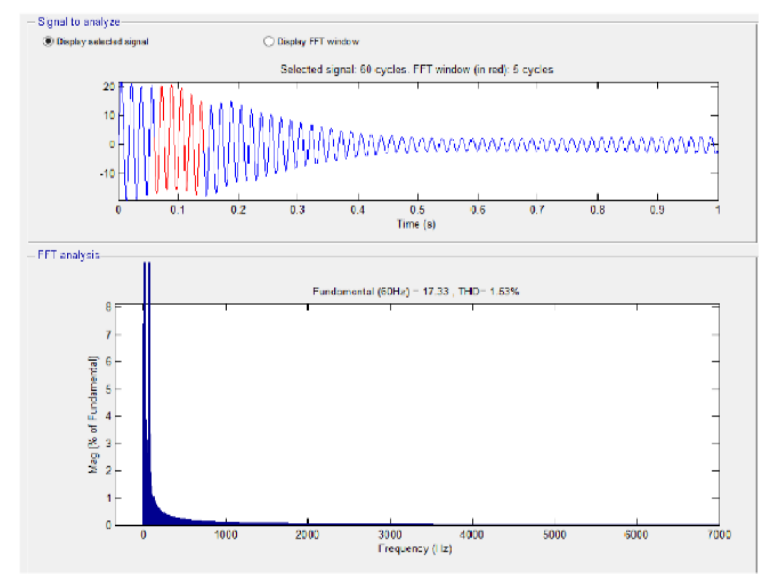

Fig. 6.10 THD plot of the system with PID controller THD=1.53\%

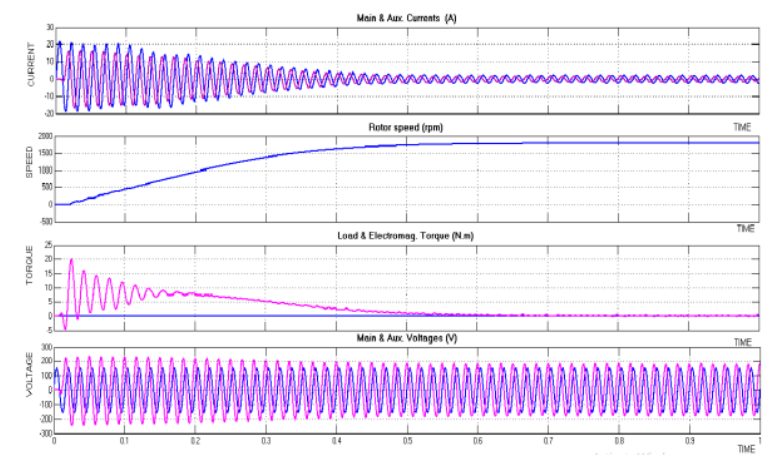

Fig. 6.11 Auxiliary and main currents, voltages, torque and speed of the induction motor with FUZZY controller 


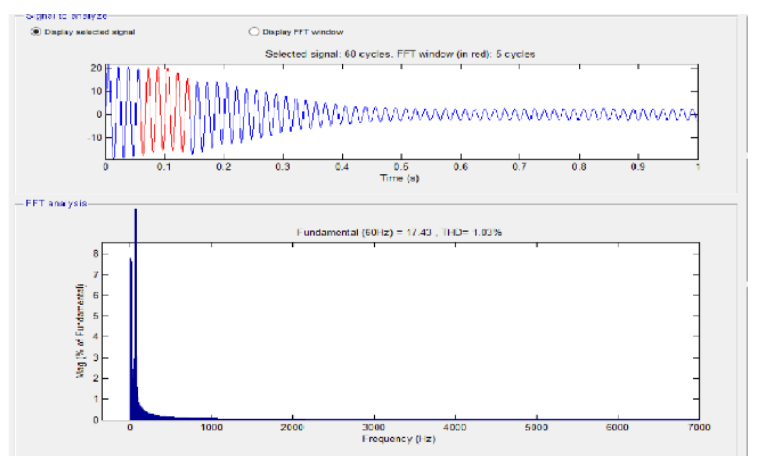

Fig. 6.12 THD plot of the system with FUZZY controller THD=1.03\%

\section{CONCLUSION}

In this paper proposes design and comparison of closed loop solar water pumping system with PID and FUZZY .This model presents the simulation of a solar powered induction motor drive for pump irrigation. To select the ratings of the various components using harmonice limination technique, the simulation of the unified system can be used. The inverter firing signal have been designed for reduction of lower order harmonics. This helps in reducing unnecessary heat created by lower order harmonic currents and enables better utilization of the induction motor. By using a single phase bridge inverter the possibility of utilizing a pv cell isto supply a single-phase induction motor. The performance of the system PID and FUZZY controllers are compared from this we can conclude that system with FUZZY controller has better efficiency as compared to system with PID controller. The proposed method can be used to relate input quantities like solar array voltage current to outputs like speed, torque. By using he simulation results we can analyze the pv pumping system with solar energy.

\section{REFERENCES}

[1] Muhammad H. Rashid. Power Electronics circuit devices, and applications. Third edition. Prentic Hall of India.

[2] MohanlalKolhe, J. C. Joshi, and D. P. Kothari,senior member, IEEE. Preformance analysis of a directly coupled solar water pumping system IEEE transactions on energy coversion vol. 19 , no. 3, september 2004

[3] G.Uma Devi, P.Manikandan, "Implementation of multilevel Inverter using Sinusoidal Pulse Width Modulation technique ,IJSETR Volume2,Issue 7,July 2013.

[4] R. M. Hillowala and A. M. Sharaf. Single phase induction motor drive scheme for pump irrigation using photovoltaic sourceDept. of Electrical Engineering. University of new Brunswick Frederiction NB Canada.

[5] B.ChittiBabu, R. SudharshanKaarthik, Nayan Kumar Dalei, R.Vigneshwaran, Rabi Narayan Das Department of Electrical Engineering, National Institute of Technology.

[6] Photovoltaic Energy Conversion system for Water Pumping Applications - Modeling and Simulation. Presented in international symposium on Photovoltaic science and technology Indian Institute of Technology, Kanpur 13 January-2010.

[7] Chetan Singh Solanki. Solar Photovoltaics, Fundamentals, Technologies and Applications, Second edition. Indian Institute of technology Bombay.

\section{BIOGRAPHIES}

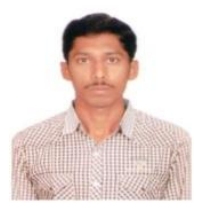

Mr. Achanti Gopi Krishna was born in Guntur, AP on June 28, 1994.He graduated from QIS College of Engineering and Technology, Ongole. His special fields of interest included Power electronics \& electrical drives Presently He is studying M.Tech in Vignan's Lara Institute of Technology \& Science, Guntur.

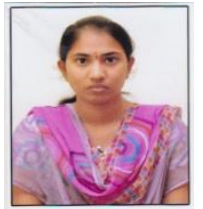

Ms. M. Divya was born in Tenali, AP, on October 20 1991. She graduated from the Jawaharlal Nehru Technological University, Kakinada and completed her post graduation in Vignan's University. Presently she is working as an Asst Prof in Vignan's Lara Institute Of Technology \& Science, Guntur and pursuing Ph.D in Vignan's University. So far she is having 2 Years of Teaching Experience. Her special fields of interest includes power electronics\& drives, renewable energy resources. 